\title{
THE BRITISH JOURNAL
}

\author{
OF \\ OPHTHALMOLOGY
}

OCTOBER, 1935

\section{COMMUNICATIONS}

\author{
SUBJECTIVE "LIGHTNING STREAKS" \\ BY
}

R. Foster MOORE

LONDON

THE following is a short note of a sharp-cut symptom complex which must be familiar to everyone, for it is of fairly common occurrence, and to the patient is a striking phenomenon .

The symptoms are the occurrence of flashes of light, almost always compared to lightning, seen periodically for a few weeks or a month or two, almost invariably referred to the temporal side of the field of vision; they are most conspicuous, as would be expected, in the dark, and are either accompanied or followed by the appearance of spots before the eyes. The symptoms are so striking and the patient is often so insistent upon them that I used systematically to dilate the pupils and to take the visual fields in fear lest they might indicate some early organic retinal lesion, such as a commencing detachment, vascular disease, or perhaps an early neoplasm.

For some reason or another they are commoner in females than in males, and mostly occur at or after middle age.

For the last two years I have instituted a cross reference of the symptom and so have collected twenty-six cases. Of these twentyone were women, five men; the average age was sixty-three years, and the youngest was forty-two; the right eye was affected nine times, the left thirteen times, and both eyes three times.

The following may be taken as typical examples of the symptoms complained of :-

W. B.-Flashes of light just like lightning to the outer side of the right eye, now becoming thinner. First saw them in the 
daylight and now chiefly come on at 5.30 p.m. Seen every day for the last three months. At first they were like thick and vivid streaks of lightning.

S.-Flashes of light quite like lightning to outer side of right eye. A few days later spots appeared before it.

C. M.-Ten days ago noticed streaks before the left eye like lightning. Sometimes they go on for several hours. Sometimes to the outer side vertically, sometimes obliquely, sometimes horizontally. They come on quite suddenly and are unlike anything she has had before. They were preceded in the first place by a thing like a spider's web.

A. D. N.-Flashes of light vertically to the outer side of the right eye, followed by fresh muscae. Flashes ceased after about a fortnight. Similar ones appeared in the left eye, and in this eye they are like arcs, curved, and to the lower outer side. Mostly at night. Has always seen black spots before this eye but they have not increased.

L. A. B.-Bright lights like lightning to outer side of the right eye. Since then a black spot has moved about but the lightning has gone off.

M.-A year ago slits of light to outer side of the left eye and spots before it ever since.

L.-Three weeks ago a smut appeared before the left eye and lightning flashes to its outer side, probably at the same time as the smut. Only. seen on a dark night. Vitreous opacities are visible.

M. J. N.-Three weeks ago suddenly saw flashes of light to the right of the right eye.

H. M.-Four days ago, whilst playing cards, saw quite suddenly what looked like a shooting star to the left of the left eye. When he got home he noticed a light like the reflection of a head-light coming towards him. This he still sees but it is fainter. The morning after the first appearance of the light he noticed a film which he was quite sure was not there the previous morning. Vitreous opacities are present.

W.-Muscae and very bright firework-like sparks to the outer side of the eyes when in the dark.

J. W. B.-Twelve days ago a regular show of fireworks before the right eye. At first thought they were fireflies and used to grab at them. He lived in India at one time and so was familiar with fireflies. The flashes began at dusk, always the same direction, always exactly the same slope as if on a line. Visible vitreous opacities in the right eye only.

E. G. G.-Last night for the first time just as she turned off the light on getting into bed saw flashes of light to the temporal side of the right eye. It was quite a striking phenomenon and as quick as lightning. Vitreous opacities are visible. 
J.-Streaks of silver lightning to the outer side of the left eye for a week. Spots before the left eye for years but worse for three weeks.

A. F.-A month ago suddenly, while in a cold east wind pain in the left eye and afterwards flashes of light to the outer side like lightning. Now seen only on turning the head to the left and only in the dark. For two days afterwards saw a black speck before the left eye.

A. B.-Four days ago noticed flashes of light at the outer corner of the left eye; was reading at the time. The lights have gradually tailed off until now they are little bother. Black spots became visible immediately following the appearance of the flashes.

K.- One month flashes of lightning to the extreme outer side of the left eye, perhaps twenty times a day. So quick she cannot say whether they are vertical. Gets into the way of looking to the left to see if anything is there. Also has a sort of quivering to outer side of left eye independently of the lightning.

W. G.-Streaks of light to the outer side of the left eye since being struck by a piece of wood. Vitreous opacities visible.

L. B.-Nineteen days after being struck in the left eye notices what he likens to the flash of flood light down and out in the left eye. Always in the same place and so much so that he looks to see if anything is there. It lasts a fraction of a second only. No change in last ten days. One fine strand in vitreous to the extreme nasal side. Nineteen days later still sees the flashes at least three or four times a day.

It will be seen that the striking features are the flash-like appearance of the lights; their position, sometimes slanting but usually vertical, and almost always to the outer side of the eyes, persisting for varying periods up to three months; and their association with the sudden development of muscae volitantes, or the presence of visible vitreous opacities. In some cases it will be noticed that the spots and the flashes are said to have appeared together, in a case or two the spots are described as having preceded the flashes, but as a rule they occur subsequently to them. In only two cases, it will be noticed, is there a history of injury.

I have traced a number of these patients sufficiently long to be sure that the symptoms are not the precursors of any serious fundus disease, for in no instance has there been any defect of the visual field or has any lesion followed.

With regard to the basic cause of the symptoms I have not been able to assure myself. I am disposed to think the likeliest cause is the gradual increase in size, and subsequent rupture of a peripheral retinal cyst, though I have no explanation to offer either of the sex incidence or of the site of the phenomenon. 